\title{
Oxford Museum of the History of Science
}

$\mathrm{T}$

HE historic interest of the Old Ashmolean, Oxford, and the association of the founder of the original Musceum Ashmoleanum with the pioneer promoters of the new philosophy whose names were inscribed as original fellows of the Royal Society, have been referred to on many occasions in these columns, particularly in connexion with the unceasing labours of Dr. R. T. Gunther to establish a Museum for the History of Science in the Old Ashmolean Building. The purposes and scope of this Museum are not, however, widely known, so that the sequence of events which have led to the appeal for financial support in The Times of June 21 may be of interest.

In 1924, the University accepted from Dr. Lewis Evans the gift of a valuable collection of astrolabes and other astronomical and mathematical instruments. The donor was a member of a remarkable family, responsible for a number of entries in the "Dictionary of National Biography". He was the brother of Sir Arthur Evans, son of Sir John Evans and great-grandson of the Rev. Lewis Evans, F.R.S. (1755-1827) who became mathematical instructor at the Royal Military Academy, Woolwich, in 1799, and with whom the collection seems to have started. The gift might presumably have been housed in the Science Museum of the University, in the building of which Ruskin played a large part. But the donor had other ideas. The old Ashmolean Museum had been diverted from its original purpose. The collections of Elias Ashmole had been removed to more modern and commodious premises. In the vacated building, the School of Geography and the offices of the "Oxford Dictionary" had found a temporary home. Here Dr. Evans saw a suitable site for his collection, and the University accepted the condition.

In these circumstances of isolation, a museum, however small, needs a curator, and in this case an enthusiastic and energetic curator was readily found in Dr. R. T. Gunther, of Magdalen College. The next step is easily foreseen. A small museum under a keen curator has a natural tendency to grow, especially when the contents are of this particular kind. An obsolete instrument, which is a positive embarrassment in one place, becomes a valuable accession here. This is not to suggest that additions have been accepted without judicious care, or that the resulting collection is not an interesting and valuable one. The admission in the letter that it was difficult to forecast the position only a short time ago, must, therefore, be taken as a proof of candour rather than of any sense of intelligent anticipation.

It is candidly admitted that the University has other pressing needs ; and in view of the recent com. prehensive appeal on behalf of the University it seems a little difficult to understand how far the present letter claims an official character. It is signed by the Chancellor and the Vice-Chancellor; the other signatories are four Magdalen men and four Cambridge men, the last of the highest eminence in the scientific world but not perhaps very intimately acquainted with the financial position at Oxford. In the circumstances, particular importance should be attached to the unofficial element, and the plea for the Museum of the History of Science should perhaps be treated strictly on its merits, which are no doubt considerable.
An appeal of this kind raises, however, the whole question of voluntary contributions for scientific and similar purposes. Rightly or wrongly, Great Britain is committed at present to the system of voluntary hospitals. One consequence is that the bulk of public benefactions is drawn into a single channel. Very little money is left to supply the needs of culture and pure science, which elsewhere gain liberal support from voluntary sources. Here the fund is notoriously inadequate, and this fact ought always to be borne in mind when competitive claims to public assistance are put forward. The lack of means to carry on important scientific work is familiar to all those who have been connected with its administration. Thus, though the position is now rather easier through the working of international organization, for many years the Seismological Committee of the British Association was sorely hampered for want of funds. It is but fair to recall that the burden of keeping alive an infant science in Great Britain fell in that instance largely on the University of Oxford. Another example may be found in that admirable institution, the Norman Lockyer Observatory at Sidmouth, which could enlarge its activities with ease, were the necessary funds available. It is needless to multiply illustrations of a general problem.

The question arises, therefore, whether appeals to the public on behalf of individual institutions offer the most effective solution of this problem. Even the hospitals have found the advantage of organizing a central fund from which a fair distribution can be made. It seems possible that science also may have something to gain by similar action. The Government Grant Fund administered by the Royal Society is useful within a restricted range, and the same body is enabled to do more by its own endowments, which are steadily increasing. But still more could be done if the means were forthcoming. Competitive appeals, the relative merits of which can scarcely be gauged by the public, may not be the right method. It seems possible that a unified scheme administered by a competent body might produce a larger fund and a fairer distribution in accordance with the true interests of pure science. Applied science and industrial research are in a happier position, and the problem is less urgent in that field.

It is to be feared that this suggestion, even if it were found worthy of consideration, might not give much help in a case like that of the Oxford Museum of the History of Science. Just as its interests are admittedly subordinate to the needs of the teaching departments, so in a wider scheme the claims of pure research would probably take the first place. Hence the present appeal must in any event stand on its own merits, and the increasing interest taken in the history of science should ensure a satisfactory response to it. Though the main responsibility of supporting this Museum will probably fall on Oxford, the signatories to the appeal are fully justified in inviting assistance from outside the University to ensure that the Museum is provided with the relatively modest amount required for its maintenance of the valuable collections which Dr. Gunther has been so successful in bringing together, and to which he has devoted so much careful attention. 